\title{
Role of norms in variation in cancer centers' end-of-life quality: qualitative case study protocol
}

\author{
Kristin E. Knutzen ${ }^{1}$, Karen E. Schifferdecker², Genevra F. Murray ${ }^{3}$, Shama S. Alam4, Gabriel A. Brooks ${ }^{2,5,6}$, \\ Nirav S. Kapadia ${ }^{2,5,6}$, Rebecca Butcher ${ }^{2}$ and Amber E. Barnato ${ }^{2,5,6^{*}}$ (i)
}

\begin{abstract}
Background: A critical barrier to improving the quality of end-of-life (EOL) cancer care is our lack of understanding of the mechanisms underlying variation in EOL treatment intensity. This study aims to fill this gap by identifying 1) organizational and provider practice norms at major US cancer centers, and 2) how these norms influence provider decision making heuristics and patient expectations for EOL care, particularly for minority patients with advanced cancer.

Methods: This is a multi-center, qualitative case study at six National Comprehensive Cancer Network (NCCN) and National Cancer Institute (NCl) Comprehensive Cancer Centers. We will theoretically sample centers based upon National Quality Forum (NQF) endorsed EOL quality metrics and demographics to ensure heterogeneity in EOL intensity and region. A multidisciplinary team of clinician and non-clinician researchers will conduct direct observations, semi-structured interviews, and artifact collection. Participants will include: 1) cancer center and clinical service line administrators; 2) providers from medical, surgical, and radiation oncology; palliative or supportive care; intensive care; hospital medicine; and emergency medicine who see patients with cancer and have high clinical practice volume or high local influence (provider interviews and observations); and 3) adult patients with metastatic solid tumors and whom the provider would not be surprised if they died in the next 12 months and their caregivers (patient and caregiver interviews). Leadership interviews will probe about EOL institutional norms and organization. We will observe inpatient and outpatient care for two weeks. Provider interviews will use vignettes to probe explicit and implicit motivations for treatment choices. Semi-structured interviews with patients near EOL, or their family members and caregivers will explore past, current, and future decisions related to their cancer care. We will import transcribed field notes and interviews into Dedoose software for qualitative data management and analysis, and we will develop and apply a deductive and inductive codebook to the data.
\end{abstract}

Discussion: This study aims to improve our understanding of organizational and provider practice norms pertinent to EOL care in U.S. cancer centers. This research will ultimately be used to inform a provider-oriented intervention to improve EOL care for racial and ethnic minority patients with advanced cancer.

Trial registration: Clinicaltrials.gov; NCT03780816; December 19, 2018.

Keywords: End-of-life, Norms, Heuristics, Cancer, Minority health

\footnotetext{
* Correspondence: Amber.Barnato@Dartmouth.edu

${ }^{2}$ The Dartmouth Institute for Health Policy and Clinical Practice, Geisel School

of Medicine, Dartmouth College, Lebanon, NH, USA

${ }^{5}$ Department of Medicine, Geisel School of Medicine, Hanover, NH, USA

Full list of author information is available at the end of the article
}

C C The Author(s). 2020 Open Access This article is licensed under a Creative Commons Attribution 4.0 International License, which permits use, sharing, adaptation, distribution and reproduction in any medium or format, as long as you give appropriate credit to the original author(s) and the source, provide a link to the Creative Commons licence, and indicate if changes were made. The images or other third party material in this article are included in the article's Creative Commons licence, unless indicated otherwise in a credit line to the material. If material is not included in the article's Creative Commons licence and your intended use is not permitted by statutory regulation or exceeds the permitted use, you will need to obtain permission directly from the copyright holder. To view a copy of this licence, visit http://creativecommons.org/licenses/by/4.0/. The Creative Commons Public Domain Dedication waiver (http://creativecommons.org/publicdomain/zero/1.0/) applies to the data made available in this article, unless otherwise stated in a credit line to the data. 


\section{Background}

The National Academy of Medicine has identified increasingly aggressive, burdensome and expensive end-oflife (EOL) treatment as a major public health problem [1]. The American Society of Clinical Oncology and National Quality Forum (NQF) define aggressive, burdensome, and expensive EOL treatment in cancer as the receipt of chemotherapy in the last 14 days of life (NQF $\# 0210$ ), intensive care unit (ICU) admission in the last 30 days of life (NQF \#0213), and non (NQF \#0215) or late (NQF \#0216) hospice referral [2]. Such treatment adversely affects patient quality of life, quality of dying, and caregiver bereavement outcomes [3-6]. Minorities are more likely to receive such EOL treatment, [7-9] potentially in disproportion to their preferences $[10,11]$.

Despite attention focused upon integrating early palliative care into advanced cancer treatment, [12-15] ICU admission in the last 30 days of life and late hospice referral have been secularly increasing [16]. Yet not all organizations are equal: cancer centers vary by more than two-fold in these EOL intensity measures $[17,18]$. These variations cannot be explained by structural characteristics or case-mix [18]. Since centers serving a higher proportion of minority patients have systematically higher EOL intensity than centers serving a higher proportion of white patients, [11] these variations in practice patterns may contribute to racial disparities in burdensome treatment near death. Moreover, despite efforts to attribute such variation to differences in patient preferences rather than racial disparities, [19] region-level analyses suggest that the impact of these preferences on variation are likely very small $[10,20]$.

We posit that a critical barrier to improving the quality of EOL cancer care in the US - and among minorities in particular - is our lack of understanding regarding the mechanisms underlying cancer center variation in EOL treatment intensity [21]. The overarching hypothesis driving this study is that differences in local organizational and provider social norms - rules about which there is at least some degree of consensus, enforced through social sanctions [22] - are a key mechanism underlying this variation. We base this hypothesis on our preliminary work at two US academic medical center hospitals at opposite extremes of EOL treatment intensity demonstrating marked differences in norms of ICU and lifesustaining treatment decision making. These norms were found to directly [23] and indirectly [24] (via influencing patient and family treatment expectations and provider decision making heuristics) affect treatment decisions for minority and non-minority patients with advanced cancer. Norms are fruitful for study because, once understood, they are potentially malleable through explicit leadership efforts and implementation of new forms of positive and negative sanctions via social marketing interventions [25].

Our study aims to study mechanisms underlying cancer center variation in EOL treatment intensity among minority and non-minority patients using a qualitative, case study design and has two objectives. First, we will identify the local organizational and provider practice norms that influence decisions about later-line chemotherapy, hospice, and ICU use among minorities with advanced cancer at major US cancer centers. Second, we will assess the influence of these norms on patient and family expectations and provider decision making heuristics for later-line chemotherapy, hospice, and ICU use among minorities with advanced cancer at major US cancer centers. Below we describe our qualitative study design approach to meet our study objectives.

\section{Methods/design \\ The design of the study}

We chose a qualitative case study design at six sites to identify local organizational and provider practice norms that influence variation in EOL treatment intensity, particularly for minority patients. Based on 2016 Medicare claims data analyses, [26] we will recruit 6 of the 11 $\mathrm{NCI} / \mathrm{NCCN}$ designated cancer centers serving at least 15\% African American advanced cancer patients. We based our sample size on recent literature related to sample size sufficiency, recommendations to reach multi-site data saturation, and qualitative research expertise of our study team. First, our study is guided by a theory based on previous research and uses data from multiple sources to test and cross-check for confirming or disconfirming evidence of our theory, a necessary component of ensuring data sufficiency [27, 28]. In addition, conducting qualitative case studies at six sites, each of which will include over 30 interviews plus multiple observations, will produce fine-grained and rich descriptive analysis to generate and compare theoretical insights across sites, as well as across stakeholders (e.g., providers, patients) within sites [29-31]. Our target numbers for interviews and observations are well within recommendations for reaching data adequacy and saturation given our well defined study aim [32]. Lastly, research suggests that qualitative research expertise, including the quality and depth of interview process, is an important criterion to consider for assessing sample size [33]. Our site visit team has over 40 years of collective experience conducting qualitative research in healthcare topics and settings, ensuring a rigorous and thorough process at each of the six sites.

We will target National Comprehensive Cancer Network (NCCN) and National Cancer Institute (NCI) Comprehensive Cancer Centers for our study because they set national standards for high quality cancer care. 
We will engage up to six sites serving a high proportion of African American patients, ranging in EOL care intensity, and theoretically sampled, to maximize our ability to compare and contrast organizational and provider practice norms related to EOL care. We defined high proportion of minority patients as $\geq 15 \%$. We measured EOL care intensity based upon risk-adjusted metrics of EOL quality using 2016 Medicare fee-for-service claims data: receipt of chemotherapy in the last 14 days of life (NQF \#0210), intensive care unit (ICU) admission in the last 30 days of life (NQF \#0213), and non (NQF \#0215) or late (NQF \#0216) hospice referral. Our approach to calculating these EOL quality metrics has been published elsewhere [26]. Given the multivariable nature of these metrics, we use data visualization to purposively select sites for case study that maximize potential heterogeneity in practice patterns [34]. Following the principles of positive deviance sampling, [35, 36] we will sample higher versus lower EOL quality sites in a ratio of 2:1.

We will employ qualitative case study research methods in this study, including inpatient observation procedures and provider, patient, and leadership semistructured interviews, that have been previously developed and piloted [23, 24, 37-39]. We will augment these methods with outpatient and tumor board observation procedures, which we developed and tested at a nonstudy NCI-designated cancer center serving a white, rural population. We will iteratively revise all data collection procedures based on researcher experiences and thematic insights following each sampled case study site visit.

\section{Qualitative data collection}

The study team will collect 3 types of data: field notes from direct observation of inpatient and outpatient cancer care and cancer tumor boards; transcribed audiorecorded semi-structured interviews with cancer center leadership, providers, and patients, family members, and caregivers; and artifacts (Table 1). We will link all data from observations using a unique identification (ID) number. We will use a data collection form for field observations to capture provider and patient demographic information, as well as location, time, and individuals present at the encounter. In addition to relevant clinical data, observers will note socio-linguistic dimensions such as turn taking, tone, affect, body positioning, and eye contact. Artifacts collected during the site visit will include workflows, marketing/informational materials, orientation guidelines, quality reporting, and communication documents used in the cancer center.

Semi-structured interview guides for site leadership focus on institutional norms, including resources, programs, and policies related to EOL care and outcomes, as well as site-specific workflows and scheduling logistics in preparation for site visits. Cognitive mental models semi-structured interview guides for providers, which

Table 1 Data Collection Rationale

\begin{tabular}{|c|c|}
\hline Data Collection Method & Rationale \\
\hline \multirow[t]{4}{*}{ Direct observation } & To learn about EOL care for minority patients with advanced cancer, specifically how it is influenced by: \\
\hline & 1. Organizational and provider practice norms \\
\hline & 2. Provider decision making heuristics \\
\hline & 3. Patient and family expectations \\
\hline \multicolumn{2}{|l|}{ Semi-structured interviews } \\
\hline \multirow[t]{3}{*}{ Leadership } & To probe organization-level: \\
\hline & 1. Norms, including resources, programs, and policies \\
\hline & 2. Site-specific workflows and scheduling logistics \\
\hline \multirow[t]{3}{*}{ Providers } & To explore individual-level: \\
\hline & 1. Motivations, decision heuristics, and/or rationalizations \\
\hline & $\begin{array}{l}\text { 2. Unconscious beliefs and assumptions that structure advanced cancer decision making, using case } \\
\text { vignettes to prime mental models }\end{array}$ \\
\hline \multirow{3}{*}{$\begin{array}{l}\text { Patients, family members, } \\
\text { caregivers }\end{array}$} & To probe individual-level: \\
\hline & 1. Preferences for cancer care \\
\hline & 2. Past, current, and future decisions related to cancer care \\
\hline \multirow[t]{4}{*}{ Artifact collection } & $\begin{array}{l}\text { To learn how the organization standardizes workflows, marketing/informational materials, orientation guidelines, } \\
\text { quality reporting, and communication documents used in the cancer center, and how this impacts: }\end{array}$ \\
\hline & 1. Local organizational and provider practice norms \\
\hline & 2. Provider decision making heuristics \\
\hline & 3. Patient and family expectations \\
\hline
\end{tabular}


include EOL case vignettes, explore motivations, decision heuristics, and/or rationalizations [40]. Six EOL vignettes were developed by a medical oncologist, radiation oncologist, and palliative care providers to highlight key decision points common to outpatient or inpatient providers (see Table 2); each vignette has one version with a photo of an African American patient and one with a photo of a white patient. Providers will view one African American case and one white patient case to facilitate mental models debriefing and uncover unconscious beliefs and assumptions related to race that structure advanced cancer decision making. Semistructured interview guides for patients, family members, and caregivers probe past, current, and future decisions related to their cancer care.

Site visit teams will consist of $2-3$ researchers. We will identify a site-specific principal investigator (PI) at each site to help facilitate support from site leadership, and identify and recruit informants for pre site-visit interviews, and providers for site-visit observation and interviews. Up to two months in advance of the site visit, the study team will conduct leadership interviews by phone, including physician and nursing leaders, outpatient oncology practice managers, and key referral service line leaders from palliative/supportive care, hospital medicine, and intensive care. We will approach other site leaders for interviews at the suggestion of the site PI. When necessary, leadership interviews will take place during and after site visits.

One month in advance of the site visit, the study team will recruit providers for observation in the inpatient and outpatient setting. The observation schedule will involve one researcher assigned to each observed provider for a half-day observation in outpatient clinics (morning

Table 2 Vignette Summaries

\begin{tabular}{|c|c|c|}
\hline $\begin{array}{l}\text { Vignette Number and } \\
\text { Patient Race }\end{array}$ & $\begin{array}{l}\text { Setting/ } \\
\text { Specialty }\end{array}$ & Vignette Summary and Key Question \\
\hline 1. African American & \multirow[t]{2}{*}{ Inpatient } & $\begin{array}{l}\text { Summary: } 71 \text { year-old man with metastatic gastric cancer. He was living in a skilled nursing facility } \\
\text { after a long hospitalization for infection. He is now hospitalized with recurrent fever, respiratory } \\
\text { distress, and anxiety. }\end{array}$ \\
\hline 2. White & & $\begin{array}{l}\text { Key Question: How to manage anxiety and respiratory distress in a patient with advanced cancer } \\
\text { and high risk for short-term death. }\end{array}$ \\
\hline 3. African American & Inpatient & Summary: 68 year-old woman with recurrent, metastatic pancreatic cancer and mild dementia. She is \\
\hline 4. White & & $\begin{array}{l}\text { performance status, decreased appetite, and abdominal pain. Her hospital evaluation demonstrates } \\
\text { poor kidney function, low blood pressure, and rapid breathing - all worrisome for rapid constitutional } \\
\text { decline. }\end{array}$ \\
\hline
\end{tabular}
decline.

5. African American Medical Oncology

6. White

7. African American Radiation

8. White Oncology

9. African American Surgical Oncology

10. White

11. African American Outpatient 12. White
Key Question: How to manage a patient with an aggressive cancer presenting to the emergency department with multiple signs of constitutional decline.

Summary: 75 year-old man with advanced, metastatic colon cancer. He is married and lives at home with his wife. He presents to clinic with pain, weight loss, and signs of cancer progression. He asks, "Do you think the chemo is working?"

Key Question: How to answer patient questions about prognosis and next steps in treatment of advanced cancer with limited treatment options.

Summary: 75 year-old man with a new diagnosis of metastatic renal cell carcinoma. He presents with seizures, brain metastases, and lung metastases. He is unmarried and without children. His performance status is poor and he is not able to make his own health care decisions. His eldest brother is his durable power of attorney, and asks, "Doc, what would you do if he was your brother?"

Key Question: How to approach surrogate decision making about management approach for a patient with poor prognosis.

Summary: 73 year-old man with newly diagnosed non-metastatic lung cancer. He has severe lung disease and significant vascular disease from heavy smoking. He is a poor surgical candidate. He mentions that the stress of his cancer diagnosis has caused him to drink alcohol more heavily than usual and he is coughing up about 1-2 tablespoons of bright red blood daily.

Key Question: How to approach a patient with a new diagnosis of a potentially curable cancer when there are a number of red flags that the patient may do poorly with surgical treatment.

Summary: 68 year-old woman with a recent diagnosis of pancreas cancer. She has been hospitalized with weight loss, pain, and declining activity. Her evaluation shows a "borderline resectable" pancreatic cancer (initial treatment would be chemotherapy or chemoradiation, if she could tolerate this). She has been unable to eat or ambulate for the last five days, due to poor appetite and performance status. She says, "I'm a fighter, not a quitter" and "With Jesus, anything is possible." She then asks, "What comes next?"

Key Question: How to approach a patient who has a "treatable" diagnosis, but who does not have the performance status to tolerate treatment. 
or afternoon session), the emergency department (by shift), and inpatient setting (by timing of daily service or consult rounds), as well as scheduled tumor boards and family meetings. Selection criteria for providers to observe and interview focus on maximizing our ability to assess provider norms for advanced cancer care within the particular institutional context that we will explore during leadership interviews. Provider selection criteria includes providers who manage patients with: 1) metastatic solid tumors (i.e., we excluded leukemia, lymphoma, and bone marrow transplant providers) and have either 2) high volumes of patients and/or 3) high peer influence, as perceived by the site PI or other key informants. We seek to recruit medical, radiation, and surgical oncology providers as well as palliative/supportive care providers who see cancer patients (see Table 3 for target sampling frame). We also seek to recruit providers from intensive care, hospital medicine, and emergency medicine who care for acutely ill cancer patients. We present an example observation schedule in Fig. 1. We will ask all providers recruited for observation to complete an interview. Interviews with providers will occur in person during or by phone after the site visit. We will digitally record all interviews and compensate all providers for participating in an interview.

At least 2 weeks prior to the site visit, we will send flyers about the study with photos of the study team to the site PI who will facilitate posting of the flier in public settings such as waiting rooms, clinic rooms, infusion suites, and inpatient units. The purpose of this flyer is to alert non-consented individuals to our study purpose and to provide instructions for opting out.

During patient care observation, researchers will directly approach patients and their family/caregivers following introduction by the consented provider. If patients or their family/caregiver verbally consent to be interviewed, the study team member will obtain contact information to arrange for a phone interview at the

Table 3 Target Sampling Frame at Each Site

\begin{tabular}{ll}
\hline Data collection setting & $\mathrm{N}$ \\
\hline Outpatient & $3-5$ \\
Medical oncology & $3-5$ \\
Surgical oncology & $3-5$ \\
Radiation oncology & $3-5$ \\
Supportive/Palliative care & $1-3$ \\
Emergency medicine & \\
Inpatient & $1-3$ \\
Hospital medicine & $1-3$ \\
Intensive care & $1-3$ \\
Supportive/Palliative care & $1-3$ \\
Oncology consult & \\
\hline
\end{tabular}

patient, family member, or caregiver's convenience at a later date. Selection criteria for patient interviews includes: 1) adults aged 21 years or older; with 2) metastatic solid tumor; 3 ) whom the provider would not be surprised if they died in the next 12 months; and 4) seen by a consented provider. We will seek to recruit equal numbers of minority and non-minority patients. We will digitally record all interviews and compensate each participant for participating.

\section{Qualitative data analysis}

We will use a qualitative and mixed methods data analysis platform, Dedoose, to manage and analyze all transcribed field notes, interviews, and artifacts, and link relevant data to contextual information (e.g., patient and provider race; site features) (Sociocultural Research Consultants, LLC). We will develop a codebook first deductively, using our theoretical model, findings in the literature, and prior research and then inductively, through an iterative process of close readings and discussion of the data in order to identify additional codes. Three qualitative researchers will apply the codebook to the data, two who will divide and code all the data, and one who will assess reliability of coding by reviewing a subset of the coded data. All three qualitative researchers will discuss differences in coding and resolve by consensus. We will repeat the analysis process after each site visit, to conduct constant comparative analysis regarding similarities and differences between and within sites in support of study aims 1 and 2. After completion of each site visit, the study team will develop a written summary of preliminary quantitative and qualitative findings specific to the site, which will then be sent to all participants from that site, to assess initial validity of the site-specific findings. After completion of all site visits and analysis of data, we will send final study reports to participating sites.

\section{Rigor and reproducibility}

Our research team is also conscious of conducting purposefully informed and respectful research on the cancer experiences of racial and ethnic minorities, and we have taken steps to ensure scientific rigor of our approach and results through study design development and will continue to do so through data collection and data analysis. Based in a relatively non-racially diverse geographic region, our team $(N=12)$ is comprised of $25 \%$ racial and ethnic minority researchers. As such, we seek to incorporate greater diversity of racial and ethnic knowledge, as well as disciplinary perspective, through an external advisory board with deep topical expertise in cancer care, palliative care, racial and ethnic health equity, and social norms. Additionally, to address potential researcher bias, the entire study team completed implicit bias training 


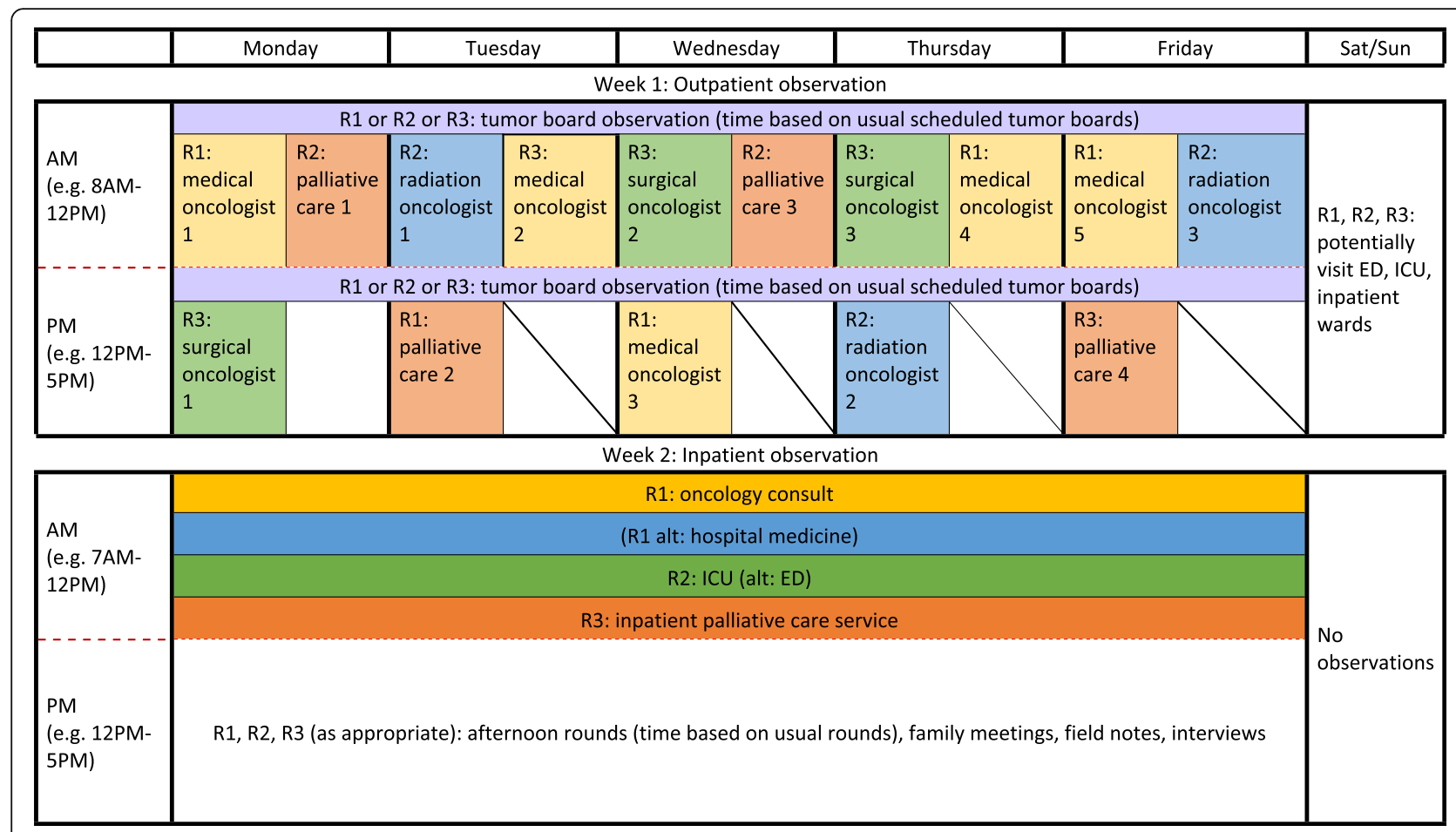

Fig. 1 Mock On-Site Observation Schedule. Researchers will ideally observe relevant outpatient clinics during week 1, and inpatient services during week 2. Researchers will go to tumor boards attended by consented providers, as well as other relevant staff meetings (e.g., fellows meetings). Researchers will observe providers during either AM or PM blocks, using the alternating daily block to dictate field notes and conduct interviews with providers and patients on-site

focused on unconscious biases related to attitudes about race, ethnicity, cancer, cancer treatment, death, and dying. One researcher participating in data collection will remain blinded to sites' EOL treatment intensity classification until data collection is complete.

Finally, we will employ multiple methods of triangulation to assure comprehensiveness and validity of data. Two to three researchers of a multidisciplinary team will participate in each site visit, and an additional three researchers will conduct qualitative analysis, to satisfy investigator triangulation. Method triangulation will include direct observation, semi-structured interviews, and artifact collection. We will achieve data triangulation by observing and interviewing leadership personnel, providers, and patients, family members, and caregivers at each site, of various backgrounds, specialties, and diagnoses, respectively. Qualitative analysis will use both deductive and inductive methods to achieve theory triangulation.

\section{Ethics approval and consent to participate}

The study has been approved by the Dartmouth College Committee for the Protection of Human Subjects (STUDY00031129) and is considered minimal risk. All participating sites will 1) waive independent IRB approval in favor of acknowledging Dartmouth's IRB, 2) rely on Dartmouth's IRB via a SMART IRB reliance, or 3) conduct a local ethical review and approval. We will obtain a waiver of informed consent for participant observation; all providers will provide written electronic consent for observation and interview, and all interviewed leadership, patients, and families will provide oral consent for interview. We have obtained a certificate of confidentiality from the National Institutes of Health (NIH) for this study.

We will not record any identifiable or personal information about providers, patients, family members, caregivers, or staff in field notes, except demographic information. A unique ID number will link data from observations and interviews, including demographic data, to consented participants. The key linking the ID number and identifying information of the consented participants will be maintained on a password-protected server. Only the research team will have access to the linkage file. All data collected on individuals will be linked to their ID number alone. We will audio-record and transcribe all handwritten field notes without any identifiable information. We will store all original field notes in a locked filing cabinet, and all transcripts on a password-protected server, to which only the research team will have access. We will give a discreet lapel pin to all providers, staff, patients, family members, and 
caregivers who do not wish to be observed, as advertised by the informational flyers posted prior to the study team's arrival at the site. We will not document any individual wearing such a pin in field notes, nor will we approach them for an interview.

We will give all individuals participating in interviews an information sheet prior to the interview, and we will obtain informed consent verbally at the time of the interview. We will obtain informed consent verbally as many of the interviews will be conducted by phone, either before or after the site visit. The process of obtaining verbal consent has been approved by the Dartmouth College Committee for the Protection of Human Subjects. We will record all interviews, and later professionally transcribe them without any identifiable information. We will store all recordings and transcripts on a password-protected server, to which only the research team will have access. Additionally, we consulted the guidelines for end-of-life research put forth in the "Methods of Researching End of Life Care" (MOREcare) project while designing the protocol for this study [41]. Specifically, we considered the risks (e.g., interviewee distress) and rewards (e.g., potential therapeutic effect) that qualitative interviews may have for patients, family members and care givers while designing these protocols.

\section{Discussion}

Our study is the first comprehensive, qualitative study of local organizational and provider norms at minorityserving NCCN and NCI-designated comprehensive US cancer centers. If the aims of this study are achieved, we expect to identify targets for institutional change at cancer centers with lower EOL quality metric performance. The two main deliverables of this research will be 1) knowledge regarding norms and their impact on EOL decision making at participating cancer centers, and 2) identification of potential members of a community research advisory board to oversee future institution-level interventions aimed at improving EOL care. Respective to the first deliverable, participating cancer centers will receive a customized report of our findings about their own center following completion of our site visit. After completion of all site visits, we will work with the American Cancer Society and participating cancer centers to identify local chapters of the American Cancer Society (ACS) and provider medical societies (e.g., county medical and nursing societies) at which we can discuss our findings and their implications for local patients and providers.

Respective to the second deliverable, we anticipate the opportunity to develop institution-level interventions aimed at EOL care in the future. Norms are fruitful for study because, once understood, they are potentially malleable through explicit leadership efforts and implementation of new forms of positive and negative sanctions. Specifically, social marketing - the use of marketing principles to influence human behavior to improve health or benefit society [25] - is a promising strategy for changing norms. Interventionists have successfully applied the principles of social marketing to change HIV risk behaviors [42, 43] and palliative care consultation use [44]. Integrating social marketing interventions in cancer centers with high intensity EOL care could have the effect of improving the quality and cost of cancer care, particularly for racial and ethnic minorities. Further, by studying norms of decision making among groups of physicians, this project will overcome the limitation of past research, which uniformly has neglected this important issue.

\section{Abbreviations \\ NCCN: National Comprehensive Cancer Network; NCl: National Cancer Institute; EOL: end-of-life; NQF: National Quality Forum; ICU: Intensive care unit; ID: Identification; PI: Principal investigator; IRB: Institutional Review Board; ACS: American Cancer Society}

\section{Acknowledgements}

Thank you to Inas Kayhal for her assistance with the cluster analysis for site sampling and associated visualizations, and to Garrett Wasp for his input on the clinical vignettes.

\section{Authors' contributions}

KEK led coordination of the study, participated in design of the protocol, contributed to instrument development, and led preparation of the manuscript. AEB led design and writing of the grant and protocol, contributed to instrument development, and participated in preparation of the manuscript. KES participated in design and writing of the grant and protocol, led instrument development, and participated in preparation of the manuscript. GFM and RB participated in design of the protocol, contributed to instrument development, and participated in preparation of the manuscript. GAB and NSK created the clinical vignettes, contributed to instrument development, and participated in design of the protocol. SSA contributed to instrument development, and participated in design of the protocol. The authors read and approved the final manuscript.

\section{Funding}

This research is funded by the American Cancer Society, grant number RSG18-017-01-CPHPS. The funding body had no role in the design of the study; and will have no role in the collection, analysis, and interpretation of data; or writing of the manuscript.

\section{Availability of data and materials}

End-of-life metrics data can be found at https://www.dartmouthatlas.org/ interactive-apps/end-of-life-cancer-care/. Qualitative data will be de-identified and made available to researchers through the NINR-funded Palliative Care Research Cooperative qualitative data repository after analyses in support of the primary aims are complete. All materials and instruments developed for this study are available by request of the authors.

Ethics approval and consent to participate

This study has been approved by the Dartmouth College Committee for the Protection of Human Subjects (STUDY00031129). This study is considered minimal risk.

Consent for publication

Not applicable. 


\section{Competing interests}

All authors declare no competing interest with respect to the research, authorship, or publication of this article.

\section{Author details}

'Department of Behavioral, Social, and Health Education Sciences, Rollins School of Public Health, Emory University, Atlanta, GA, USA. ${ }^{2}$ The Dartmouth Institute for Health Policy and Clinical Practice, Geisel School of Medicine, Dartmouth College, Lebanon, NH, USA. ${ }^{3}$ Department of General Internal Medicine, Boston Medical Center, Boston, MA, USA. ${ }^{4}$ Evidera, Pharmaceutical Product Development, Bethesda, MD, USA. ${ }^{5}$ Department of Medicine, Geisel School of Medicine, Hanover, NH, USA. ${ }^{6}$ Norris Cotton Cancer Center at Dartmouth-Hitchcock Medical Center, Lebanon, NH, USA.

\section{Received: 1 July 2020 Accepted: 16 August 2020} Published online: 27 August 2020

\section{References}

1. Institute of Medicine. Dying in America: Improving Quality and Honoring Individual Preferences Near the End of Life. Washington, DC: The National Academies Press; 2015. https://doi.org/10.17226/18748.

2. National Quality Forum. National Quality Forum Quality Positioning System; 2018. [cited 2020 Apr 2]. Available from: https://www.qualityforum.org/QPS/ QPSTool.aspx.

3. Teno JM, Curtis JR. Family perspectives on aggressive cancer care near the end of life. JAMA Oncol. 2016;2(7):957-8.

4. Wright AA, Keating NL, Ayanian JZ, Chrischilles EA, Kahn KL, Ritchie CS, et al. Family perspectives on aggressive cancer care near the end of life. JAMA - J Am Med Assoc. 2016;315(3):284-92 [cited 2020 Apr 2]. Available from: http://www.ncbi.nlm.nih.gov/pubmed/26784776.

5. Wright AA, Zhang B, Ray A, Mack JW, Trice E, Balboni T, et al. Associations between end-of-life discussions, patient mental health, medical care near death, and caregiver bereavement adjustment. JAMA - J Am Med Assoc. 2008;300(14):1665-73.

6. Prigerson HG, Bao Y, Shah MA, Elizabeth Paulk M, LeBlanc TW, Schneider BJ, et al. Chemotherapy use, performance status, and quality of life at the end of life. JAMA Oncol. 2015;1 (6):778-84.

7. Check DK, Samuel CA, Rosenstein DL, Dusetzina SB. Investigation of racial disparities in early supportlVe medication use and end-of-life care among medicare beneficiaries with stage IV breast cancer. J Clin Oncol. 2016;34(19): 2265-70 [cited 2020 Apr 2]. Available from: http://www.ncbi.nlm.nih.gov/ pubmed/27161968.

8. Barnato $A E$, Chang $\mathrm{CCH}$, Saynina $\mathrm{O}$, Garber AM. Influence of race on inpatient treatment intensity at the end of life. J Gen Intern Med. 2007;22(3): 338-45.

9. Byhoff E, Harris JA, Langa KM, Iwashyna TJ. Racial and ethnic differences in end-of-life Medicare expenditures. J Am Geriatr Soc. 2016;64(9):1789-97.

10. Barnato AE, Anthony DL, Skinner J, Gallagher PM, Fisher ES. Racial and ethnic differences in preferences for end-of-life treatment. J Gen Intern Med. 2009;24(6):695-701 [cited 2020 Apr 2]. Available from: http://www. ncbi.nlm.nih.gov/pubmed/19387750.

11. Barnato AE, Berhane Z, Weissfeld LA, Chang CCH, Linde-Zwirble WT, Angus DC. Racial variation in end-of-life intensive care use: a race or hospital effect? Health Serv Res. 2006;41(6):2219-37 [cited 2020 Apr 2]. Available from: http://www.ncbi.n/m.nih.gov/pubmed/17116117.

12. Bakitas MA, Tosteson TD, Li Z, Lyons KD, Hull JG, Li Z, et al. Early versus delayed initiation of concurrent palliative oncology care: patient outcomes in the ENABLE III randomized controlled trial. J Clin Oncol. 2015;33(13): 1438-45 [cited 2020 Apr 2]. Available from: http://www.ncbi.n/m.nih.gov/ pubmed/25800768.

13. Parikh RB, Kirch RA, Smith TJ, Temel JS. Early specialty palliative care translating data in oncology into practice. N Engl J Med. 2013;369(24):234751 [cited 2020 Apr 2]. Available from: http://www.ncbi.nlm.nih.gov/ pubmed/24328469.

14. Temel JS, Greer JA, Muzikansky A, Gallagher ER, Admane S, Jackson VA, et al. Early palliative care for patients with metastatic non-small-cell lung cancer. N Engl J Med. 2010;363(8):733-42.

15. Zimmermann C, Swami N, Krzyzanowska M, Hannon B, Leighl N, Oza A, et al. Early palliative care for patients with advanced cancer: a clusterrandomised controlled trial. Lancet. 2014:383(9930):1721-30 [cited 2020 Apr 2]. Available from: http://www.ncbi.nlm.nih.gov/pubmed/24559581.
16. Teno JM, Gozalo PL, Bynum JPW, Leland NE, Miller SC, Morden NE, et al Change in end-of-life care for medicare beneficiaries: site of death, place of care, and health care transitions in 2000, 2005, and 2009. JAMA - J Am Med Assoc. 2013;309(5):470-7 [cited 2020 Apr 2]. Available from: http://www. ncbi.nlm.nih.gov/pubmed/23385273.

17. Goodman DC, Fisher ES, Chang C-H, Morden NE, Jacobson JO, Murray K, et al. A report of the Dartmouth atlas project quality of end-of-life cancer care for Medicare beneficiaries regional and hospital-specific analyses; 2010. [cited 2020 Apr 2]. Available from: www.dartmouthatlas.org.

18. Morden NE, Chang CH, Jacobson JO, Berke EM, Bynum JPW, Murray KM, et al. The care span: end-of-life care for medicare beneficiaries with cancer is highly intensive overall and varies widely. Health Aff. 2012;31(4):786-96 [cited 2020 Apr 2]. Available from: http://www.ncbi.nlm.nih.gov/ pubmed/22492896.

19. Institute of Medicine (US) Committee on Understanding and Eliminating Racial and Ethnic Disparities in Health Care. In: Smedley BD, Stith AY, Nelson $A R$, editors. Unequal treatment: confronting racial and ethnic disparities in health care. Washington (DC): National Academies Press (US); 2003.

20. Baker LC, Bundorf MK, Kessler DP. Patients' preferences explain a small but significant share of regional variation in medicare spending. Health Aff. 2014;33(6):957-63 [cited 2020 Apr 2]. Available from: http://www.ncbi.nIm. nih.gov/pubmed/24889944.

21. Keating NL, Herrinton L, Zaslavsky AM, Liu L, Ayanian JZ. Variations in hospice use among cancer patients. J Natl Cancer Inst. 2006;98(15):1053-9.

22. Horne C. Sociological perspectives on the emergence of social norms. In: Hechter M, Opp KD, editors. Social norms. New York: Russel Sage; 2001. p. 3-34.

23. Barnato AE, Tate JA, Rodriguez KL, Zickmund SL, Arnold RM. Norms of decision making in the ICU: a case study of two academic medical centers at the extremes of end-of-life treatment intensity. Intensive Care Med. 2012; 38(11):1886-96 [cited 2020 Apr 2]. Available from: http://www.ncbi.nlm.nih. gov/pubmed/22940755.

24. Barnato AE, Mohan D, Lane RK, Huang YM, Angus DC, Farris C, et al. Advance care planning norms may contribute to hospital variation in endof-life ICU use: a simulation study. Med Decis Making. 2014;34(4):473-84 [cited 2020 Apr 2]. Available from: http://www.ncbi.nlm.nih.gov/ pubmed/24615275.

25. Weinreich NK. Hands-on social marketing: a step-by-step guide to designing change for good. Thousand Oaks: SAGE Publications; 2011. p. 309.

26. Wasp GT, Alam SS, Brooks GA, Khayal IS, Kapadia NS, Carmichael DQ, et al. End-of-life quality metrics among medicare decedents at minorityserving cancer centers: a retrospective study. Cancer Med. 2020;9(5): 1911-21 [cited 2020 Apr 3]. Available from: http://www.ncbi.nlm.nih. gov/pubmed/31925998.

27. Malterud K, Siersma VD, Guassora AD. Sample size in qualitative interview studies: guided by information power. Qual Health Res. 2016;26(13):1753-60.

28. Vasileiou K, Barnett J, Thorpe S, Young T. Characterising and justifying sample size sufficiency in interview-based studies: systematic analysis of qualitative health research over a 15-year period. BMC Med Res Methodol. 2018;18(1):148 [cited 2020 May 13]. Available from: https://bmcmedresmethodol.biomedcentral.com/articles/1 0.1186/s12874-018-0594-7.

29. Glaser BG, Strauss AL. The discovery of grounded theory : strategies for qualitative research. Chicago: Aldine Publishing; 1967. p. 271.

30. Giacomini MK, Cook DJ, Guyatt GH. Users' guides to the medical literature: XXIII. Qualitative research in health care B. what are the results and flow do they help me care for my patients? JAMA. 2000;284(4):478-82 [cited 2020 Apr 2]. Available from: http://www.ncbi.nlm.nih.gov/pubmed/10904512.

31. Sofaer S. Qualitative methods: what are they and why use them? Health Serv Res. 1999;34(5 Pt 2):1101-18 [cited 2020 Apr 2]. Available from: http:// www.ncbi.nlm.nih.gov/pubmed/10591275.

32. Hagaman AK, Wutich A. How many interviews are enough to identify Metathemes in multisited and cross-cultural research? Another perspective on guest, bunce, and Johnson's (2006) landmark study. Field Methods. 2017; 29(1):23-41 [cited 2020 May 13]. Available from: http://journals.sagepub. com/doi/10.1177/1525822X16640447.

33. Morse JM. Determining sample size. Qual Health Res. 2000;10(1):3-5 [cited 2020 May 13]. Available from: http//journals.sagepub.com/doi/10.1177/10497320012911 8183.

34. Ware C. Information visualization: perception for design. 4th ed. Cambridge: Morgan Kaufmann; 2019. 
35. Bradley EH, Curry LA, Ramanadhan S, Rowe L, Nembhard IM, Krumholz HM. Research in action: using positive deviance to improve quality of health care. Implement Sci. 2009;4(1):25.

36. Marsh DR, Schroeder DG, Dearden KA, Sternin J, Sternin M. The power of positive deviance. Br Med J. 2004;329:1177-9.

37. Elliott AM, Alexander SC, Mescher CA, Mohan D, Barnato AE. Differences in physicians' verbal and nonverbal communication with black and white patients at the end of life. J Pain Symptom Manage. 2016;51(1):1-8 [cited 2020 Apr 2]. Available from: http://www.ncbin.nlm.nih.gov/pubmed/26297851.

38. Barnato AE, Hsu HE, Bryce CL, Lave JR, Emlet LL, Angus DC, et al. Using simulation to isolate physician variation in intensive care unit admission decision making for critically ill elders with end-stage cancer: a pilot feasibility study. Crit Care Med. 2008:36(12):3156-63 [cited 2020 Apr 2] Available from: http://www.ncbi.nlm.nih.gov/pubmed/18936694.

39. Barnato AE, Mohan D, Downs J, Bryce CL, Angus DC, Arnold RM. A randomized trial of the effect of patient race on physicians' intensive care unit and life-sustaining treatment decisions for an acutely unstable elder with end-stage cancer. Crit Care Med. 2011;39(7):1663-9 [cited 2020 Apr 2] Available from: http://www.ncbi.nIm.nih.gov/pubmed/21460710.

40. Morgan MG, Fischhoff B, Bostrom A, Atman CJ. Risk communication: a mental models approach. Cambridge: Cambridge University Press; 2002.

41. Higginson IJ, Evans CJ, Grande G, Preston N, Morgan M, McCrone P, et al. Evaluating complex interventions in end of life care: the MORECare statement on good practice generated by a synthesis of transparent expert consultations and systematic reviews. BMC Med. 2013;11(1):111 [cited 2020 Apr 2]. Available from: http://bmcmedicine.biomedcentral.com/articles/10.11 86/1741-7015-11-111.

42. Broadhead RS, Heckathorn DD, Weakliem DL, Anthony DL, Madray H, Mills RJ, et al. Harnessing peer networks as an instrument for AIDS prevention: results from a peer-driven intervention. Public Health Rep. 1998;1 13(SUPPL. 1):42-57.

43. Heckathorn DD, Broadhead RS, Anthony DL, Weakliem DL. Aids and social networks: Hiv prevention through network mobilization. Sociol Focus. 1999; 32(2):159-79.

44. Center to Advance Palliative Care. Marketing and Messaging Palliative Care | Center to Advance Palliative Care. [cited 2020 Apr 2]. Available from: https:// www.capc.org/toolkits/marketing-and-messaging-palliative-care/.

\section{Publisher's Note}

Springer Nature remains neutral with regard to jurisdictional claims in published maps and institutional affiliations.

Ready to submit your research? Choose BMC and benefit from:

- fast, convenient online submission

- thorough peer review by experienced researchers in your field

- rapid publication on acceptance

- support for research data, including large and complex data types

- gold Open Access which fosters wider collaboration and increased citations

- maximum visibility for your research: over $100 \mathrm{M}$ website views per year

At $\mathrm{BMC}$, research is always in progress.

Learn more biomedcentral.com/submissions 